\title{
Primary headache disorders in the adult general population of Pakistan - a cross sectional nationwide prevalence survey
}

\author{
A. A. Herekar ${ }^{1,2}$, A. Ahmad ${ }^{1,3}$, U. L. Uqaili, ${ }^{1,3}$, B. Ahmed ${ }^{1,4}$, J. Effendi ${ }^{1,3}$, S. Z. Alvi ${ }^{1,5}$, M. A. Shahab ${ }^{6}$, U. Javed \\ A. D. Herekar ${ }^{1,8}$, Rafiq Khanani ${ }^{9}$ and T. J. Steiner ${ }^{10,11^{*}}$
}

\begin{abstract}
Background: The large geographical gaps in our knowledge of the prevalence and burden of headache disorders include almost all of Eastern Mediterranean Region (EMR). We report a nationwide population-based study in Pakistan, an EMR country with the sixth largest population in the world, conducted as a project within the Global Campaign against Headache.
\end{abstract}

Methods: We surveyed six locations from the four provinces of Pakistan: Punjab, Sindh, Khyber Pakhtunkhwa and Baluchistan. We randomly selected and visited rural and urban households in each. One adult member (18-65 years) of each household, also randomly selected, was interviewed by a trained non-medical interviewer from the same location using a previously-validated structured questionnaire translated into Urdu, the national language. We estimated 1-year prevalences of the headache disorders of public-health importance and examined their associations with demographic variables using multivariate analysis.

Results: There were 4223 participants (mean age $34.4 \pm 11.0$ years; male 1957 [46.3\%], female 2266 [53.7\%]; urban 1443 [34.2\%], rural 2780 [65.8\%]]. Participation proportion was 89.5\%. Headache in the previous year was reported by 3233 (76.6\% [95\% Cl: 75.3-77.8\%]). The age- and gender-adjusted 1-year prevalence of migraine was 22.5\% [21.2-23.8\%] (male 18.0\% [16.8-19.2\%], female 26.9\% [25.6-28.2\%]), of tension-type headache (TTH) 44.6\% [43.1-46.1\%] (male 51.2\% [49.7-52.7\%], female 37.9\% [36.4-39.4\%]), of probable medication-overuse headache 0.7\% [0.5-1.0\%] (male 0.7\% [0.5-1.0\%], female $0.8 \%$ [0.5-1.1\%]) and of other headache on $\geq 15$ days/month 7.4\% [6.6-8.2\%] (male 4.4\% [3.8-5.0\%], female 10.4\% [9.5-11.3\%]). Migraine was more prevalent in females by a factor of $3: 2$ although this association barely survived $(P=0.039)$ after correcting for other factors. TTH was more prevalent in males by about 4:3 $(P=0.026)$. All headache and migraine were age-related, peaking in the age group 40-49 years; $T \mathrm{TH}$ peaked a decade earlier. Higher education $(P=0.004)$ and income $(P=0.001)$ were negatively associated with prevalence of migraine.

Conclusion: With three quarters of its population affected, headache disorders must be on the public-health agenda of Pakistan. Worldwide, these disorders are the third leading cause of disability; information from specific enquiry into the burden attributable to headache disorders in this country is needed to inform health policy and priority-setting, and will be reported soon.

Keywords: Headache disorders, Migraine, Tension-type headache, Medication-overuse headache, Epidemiology, Prevalence, Population-based survey, Eastern Mediterranean Region, Pakistan, Global campaign against headache

\footnotetext{
* Correspondence: t.steiner@imperial.ac.uk

${ }^{10}$ Department of Neuroscience, Norwegian University of Science and

Technology (NTNU), Edvard Griegs Gate, NO-7491 Trondheim, Norway

${ }^{11}$ Division of Brain Sciences, Imperial College London, London, UK

Full list of author information is available at the end of the article
} 


\section{Background}

Headache disorders affect almost half the world's population, according to a survey of the published literature conducted nine years ago [1]. Tension-type headache (TTH) and migraine are the major contributors in terms of prevalence, being the second and third most common disorders in the world [2]. In 2013, migraine was recognised as the sixth-highest cause of disability in the world [3]. Also important in public-health terms, because of the burdens they impose at individual level, are the group of disorders characterized by headache on $\geq 15$ days/month; these include medication-overuse headache $(\mathrm{MOH})$, not itself a primary headache disorder but, in almost all cases, a sequela due to mismanagement of either migraine or $\mathrm{TTH}$ [4]. $\mathrm{MOH}$ is the $18^{\text {th }}$-highest cause of disability in the world [3].

Large geographical gaps in our knowledge of the prevalence and burden of headache disorders have been evident from the various surveys $[1,2,5,6]$. In a continuing endeavour to fill these, Lifting The Burden (LTB), a United Kingdom-based non-governmental organisation conducting the Global Campaign against Headache [7] in official relations with the World Health Organization [8], has been supporting population-based studies in many parts of the world: among others, in Russia in Eastern Europe [9], in China in the Western Pacific Region [10] and in India [11] and Nepal [12] in South East Asia. Over 2.5 billion people live in these countries, where knowledge was virtually absent. In the Eastern Mediterranean Region is another large geographical knowledge gap; the countries include Pakistan, with the sixth largest population in the world [13] and characterised by economic and political instability and, in parts, by geographical inaccessibility.

We report here the prevalence results of a nationwide cross-sectional population-based survey in Pakistan. It was conducted as part of the series of similar studies within the Global Campaign against Headache, and following the standardized methodology developed by LTB for such studies [14]. It is the first to be published from the Region. Its two purposes were to contribute to knowledge of the global burden of headache [3] and to provide evidence for national health policy in Pakistan.

\section{Methods}

The detailed methodology has been published previously [15]. Here the methods are summarized.

\section{Ethics}

The Ethics Review Board of the Dow University of Health Sciences approved the study protocol. All participants were informed about the nature and purpose of the survey and gave their consent to taking part. Data protection legislation was complied with.

\section{Survey}

We conducted the survey in six locations purposively selected from the four provinces of Pakistan to represent the national population: Lahore and Multan (Punjab), Karachi and Sukkur (Sindh), Abbottabad (Khyber Pakhtunkhwa) and Gwadar (Baluchistan). Rural and urban households randomly selected in each location were visited unannounced by a team of 12 trained non-medical interviewers recruited from, and therefore familiar with, the same locations. One randomly-selected adult member (18-65 years) of each household was interviewed using LTB's structured HARDSHIP questionnaire translated into Urdu, the national language. This questionnaire, used in similar studies conducted in other countries [16], included demographic enquiry, screening and diagnostic questions for headache. Additionally, weight and height were measured, and body mass index (BMI) calculated.

\section{Diagnosis}

Diagnoses were not made by the interviewers, but subsequently by diagnostic algorithm [16], applied to the most bothersome headache if a participant reported more than one type of headache. The diagnostic questions had been validated earlier in a Pakistani population [15]. Cases were removed for individual review of medication use when headache was reported on $\geq 15$ days/month, and diagnosed either as probable $\mathrm{MOH}(\mathrm{pMOH})$ or other headache on $\geq 15$ days/month. All remaining cases (episodic headache) were classified by applying modified ICHD-II criteria in hierarchical sequence: first definite migraine, then definite $\mathrm{TTH}$, then probable migraine and finally probable TTH. Cases falling into none of these categories were unclassified. During subsequent analysis, definite and probable migraine were combined, as were definite and probable $\mathrm{TTH}$, for generating prevalence estimates for migraine and TTH. The correctness of this approach has been argued [14].

\section{Data management}

Data from completed questionnaires were entered into SPSS version 16.0. We applied full double data-entry by two operators working independently, subsequently eliminating errors by reference to the original forms.

\section{Statistics}

We planned a total sample size of 4149. In calculating this we assumed a headache prevalence of $50 \%$ and applied a confidence level of $99 \%$ and confidence interval (CI) of $2 \%$.

Data analysis was conducted using Stata/SE 12.0 and SPSS v 23. Continuous variables were summarized as means and standard deviations (SDs), and categorical variables as numbers and percentages. 
We categorised age as $18-29,30-39,40-49,50-59$ or 60-65 years; marital status as "single", "married" or "divorced, widowed or separated"; habitation as "urban" or "rural"; educational level as "none", "some schooling" (up to high school) or "college" (including university); income level as "poor" or "not poor" ("poor" meaning below the poverty line $\left[30^{\text {th }}\right.$ population income percentile, or income per quarter of $<$ PKR 9,000 or USD 90] [17]); BMI according to the WHO classification [18] as "underweight" (<18.5), "normal” (18.5-24.9), “overweight" (25.0-29.9), "obese" (30-39.9) or "morbidly obese" (>40).

We used chi-squared to compare distributions between categorical variables. We calculated headache prevalences as percentages with $95 \%$ CIs. We performed bivariate analyses, calculating odds ratios (ORs) with 95\% CIs, to look for associations between headache types (migraine, TTH or all headache on $\geq 15$ days/month) and demographic variables. In subsequent multivariate logistic regression analyses, we calculated $\operatorname{Exp}(\mathrm{B})$ with $95 \%$ CIs taking prevalence of each headache type as the dependent variable and gender, age, marital status, habitation, education level, income, province and BMI as factors. Model-fitting statistics indicated a good fit (chi-squared $=501.98, \mathrm{df}=60, P<$ 0.001 ). In the principal (prevalence) and bivariate association analyses we set statistical significance at $P<0.05$; in the multivariate analysis, because of multiple comparisons we set it at $P<0.02$.

\section{Quality assurance}

We applied preventative, detective and corrective quality assurance procedures as described elsewhere [15]. During the data verification process, irregularities in data collection were identified in one location, Multan, and rectified, which necessitated discarding the original (fraudulent) data and repeating the survey in this location (a full account of this has been published elsewhere [19]). The results reported here include the data from the second survey in Multan.

\section{Results}

The survey was completed by 4223 participants (1957 [46.3\%] male, 2266 [53.7\%] female) aged 18-65 years (mean $34.4 \pm 11.0$ ), of whom $1443(34.2 \%)$ lived in urban and $2780(65.8 \%)$ in rural areas. The participation proportion was $89.5 \%$ overall, with regional variation between $69 \%$ and $>99 \%$. The sample was generally well matched to the population of all Pakistan for gender, age and urban/ rural habitation according to figures from Pakistan's last census (1998) [20], albeit with males and the over-50 age groups slightly under-represented. Most participants (72.1\%) were married, $26.0 \%$ were unmarried and only $1.9 \%$ were divorced, separated or widowed; the latter two groups were also slightly under-represented. During bivariate analysis, prevalences were adjusted for age and gender by weighting according to population data [20] since these were likely to be influencing factors.

Observed prevalences of all headache and of the specific headache types, overall and by gender, are shown in Table 1. Headache of any sort ("all headache") in the past year was reported by 3233 participants, an observed 1-year prevalence of $76.6 \%$. There was no difference between males and females. TTH was by far the most prevalent headache disorder $(44.7 \%)$, but migraine was also very common, reported by over one fifth (22.9\%) of participants. Headache on $\geq 15$ days/month was reported by almost one in 12 participants $(8.1 \%)$, of whom a small minority $(0.7 \%)$ were diagnosed as pMOH. Only 37 cases $(0.9 \%)$ were unclassifiable, similar numbers in each gender (Table 1$)$. Migraine was more prevalent in females in a ratio of 3:2 $(P<0.001)$, pMOH and other headache on $\geq 15$ days/month about twofold (the latter significantly $[P<0.001]$ but the former not). $\mathrm{TTH}$, on the other hand, was more prevalent in males by a factor of about 4:3 $(P<0.001)$ (Table 1$)$.

Relationships with age are shown in Fig. 1 and Table 2. The curves for all headache and migraine show prevalence increasing to a peak during the age range 40-49 years, then declining; prevalence of TTH peaked 10 years earlier but remained high in the $5^{\text {th }}$ decade. The observed prevalence of $\mathrm{pMOH}$ increased steadily with age, although numbers were too small to show a significant relationship.

Table 3 shows the bivariate analyses. Married participants had more overall headache $(\mathrm{OR}=1.8)$ and migraine $(\mathrm{OR}=1.5)$ than those who were single. Participants who were divorced, widowed or separated also had more headache $(\mathrm{OR}=1.9)$, migraine $(\mathrm{OR}=1.8)$ and headache on $\geq 15$ days/month $(\mathrm{OR}=2.5)$, but less TTH $(\mathrm{OR}=0.7)$ than single participants. No significant associations emerged between marital status and $\mathrm{pMOH}$.

Urban dwelling was weakly positively associated with migraine $(\mathrm{OR}=1.2)$ and more strongly with other headache on $\geq 15$ days/month $(\mathrm{OR}=1.8)$ but negatively with TTH $(\mathrm{OR}=0.7)$ (Table 3$)$.

Increasing educational level was negatively associated with migraine and other headache on $\geq 15$ days/month, and positively with TTH (Table 3). Accordingly, being not poor was negatively associated with migraine $(\mathrm{OR}=$ $0.8)$ and strongly so with other headache on $\geq 15$ days/ month $(\mathrm{OR}=0.4)$, and with all headache $(\mathrm{OR}=0.7)$, but positively with TTH $(\mathrm{OR}=1.3)$ (Table 3$)$.

BMI was calculated for 3889 participants (for 334, either height or weight was not recorded). Only a little over half of participants $(2,152 ; 55.5 \%)$ were of normal weight: over $40 \%$ were overweight $(1156 ; 29.8 \%)$ or obese $(417 ; 10.7 \%)$ and nine participants were morbidly obese. The extremes (underweight and obese) were negatively associated with all headache and TTH but positively with migraine; obesity was also positively associated with headache on $\geq 15$ days/month (Table 3 ). 
Table 1 Observed and age- and gender-adjusted 1-year prevalences of all headache and headache types

\begin{tabular}{|c|c|c|c|c|}
\hline \multirow[t]{2}{*}{ Headache type } & \multirow{2}{*}{$\begin{array}{l}\text { Observed } \\
\text { overall } \\
(N=4223) \\
(\%)[95 \% \mathrm{Cl}]\end{array}$} & \multicolumn{2}{|l|}{$\begin{array}{l}\text { Age-adjusted } \\
(\%)[95 \% \mathrm{Cl}]\end{array}$} & \multirow{2}{*}{$\begin{array}{l}\text { Age- and } \\
\text { gender-adjusted } \\
(N=4223) \\
\text { (\%) }[95 \% \mathrm{Cl}]\end{array}$} \\
\hline & & $\begin{array}{l}\text { Males } \\
(n=1957)\end{array}$ & $\begin{array}{l}\text { Females } \\
(n=2266)\end{array}$ & \\
\hline All headache & $76.6[75.3-77.9]$ & $75.4[74.1-76.7]$ & $76.8[75.5-78.1]$ & $76.1[74.8-77.4]$ \\
\hline Migraine & $22.9[21.6-24.2]$ & $18.0[16.8-19.2]$ & $26.9[25.6-28.2]$ & $22.5[21.2-23.8]$ \\
\hline Tension-type headache & $44.7[43.2-46.2]$ & $51.2[49.7-52.7]$ & $37.9[36.4-39.4]$ & $44.6[43.1-46.1]$ \\
\hline Probable medication-overuse headache & $0.7[0.5-1.0]$ & $0.7[0.5-1.0]$ & $0.9[0.6-1.2]$ & $0.8[0.5-1.1]$ \\
\hline Other headache on $\geq 15$ days/month & $7.4[6.6-7.9]$ & $4.4[3.8-5.0]$ & $10.4[9.5-11.3]$ & $7.4[6.6-8.2]$ \\
\hline Unclassifiable & $0.9[0.6-1.2]$ & $1.2[0.9-1.5]$ & $0.8[0.5-1.1]$ & $1.0[0.7-1.3]$ \\
\hline
\end{tabular}

$\mathrm{Cl}$ confidence interval. Adjusted for age and gender in SPSS v23 by weighting in accordance with the formula Weight = proportion in population/proportion in sample, taking population data from [20]

In multivariate analysis (Table 4), the positive association between female gender and migraine barely survived $(P>0.02)$, but the association with headache on $\geq 15$ days/month remained strongly significant, as did the negative association with TTH. Age 40-49 years remained positively associated with migraine, and an association emerged with headache on $>15$ days/month, while ages 30-49 were positively associated with TTH. Migraine was confirmed as more prevalent among married participants, but otherwise there were no associations with marital status. No associations with area of habitation survived. Some schooling was positively associated with TTH whereas college education continued to be strongly negatively associated with migraine. No other associations with educational level survived. Being poor remained strongly associated with both migraine and headache on $\geq 15$ days/month, but the negative association with TTH did not survive. There were regional variations: relative to the Punjab, migraine was much less common in Khyber Pakhtunkhwa and TTH was less common in all other regions, but especially in Khyber Pakhtunkhwa; on the other hand, headache on $\geq 15$ days/ month was more common in Sindh and Baluchistan. Being underweight and being obese each remained negatively associated with TTH, but no other associations with BMI survived.

\section{Discussion}

This first-ever nationwide population-based study of the prevalence of headache disorders in Pakistan (indeed, in any country in the Eastern Mediterranean Region) has revealed much headache in the country. The overall 1-year prevalence of $76.6 \%$ is substantially higher than the reported global average of $46 \%$ [1]. At $22.9 \%$ and $44.7 \%$, the prevalences of migraine and TTH each greatly exceed their respective global estimates of $14.7 \%$ and $20.7 \%$ from the Global Burden of Disease Survey 2010 [2]. Headache on $\geq 15$ days/month is highly prevalent $(8.1 \%)$, although only $0.7 \%$ of the adult population have $\mathrm{pMOH}$.

With 4223 participants, a participation proportion of $89.5 \%$, a representative sample and a well-performing diagnostic instrument [15], these estimates from Pakistan have low margins of uncertainty. The key methodological limitation was that we could not reach most slum-dwellers,

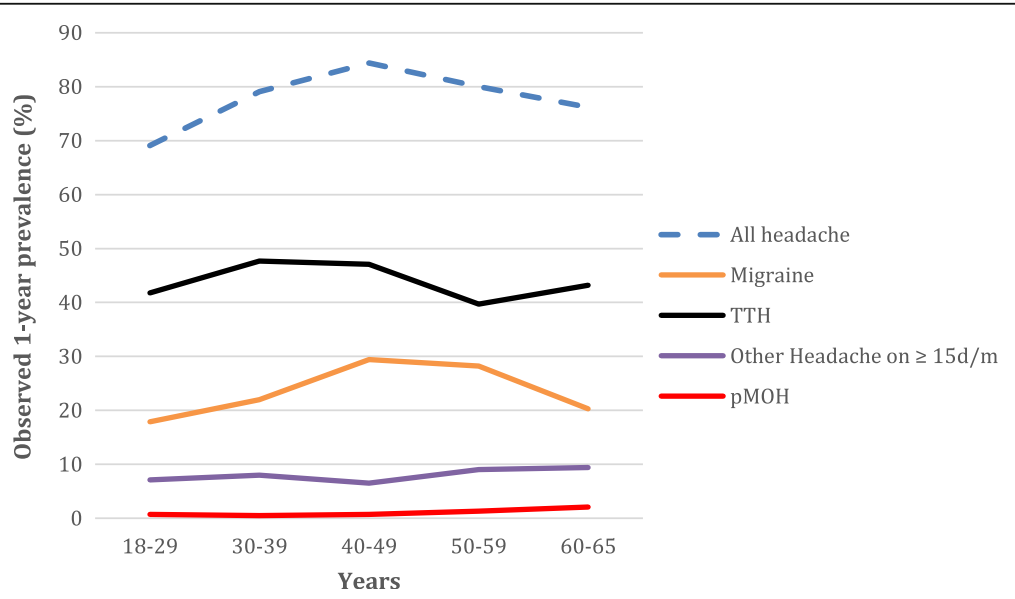

Fig. 1 Observed 1-year prevalences of headache types by age (TTH: tension-type headache; d/m: days/month; pMOH: probable medication-overuse headache) 
Table 2 Observed prevalences of migraine and tension-type headache, by age and gender

\begin{tabular}{llllll}
\hline $\begin{array}{l}\text { Age group } \\
\text { (years) }\end{array}$ & $\begin{array}{l}\text { One-year prevalence } \\
\%(\mathrm{n})\end{array}$ & & & \\
\cline { 2 - 3 } \cline { 5 - 6 } & Male & & & Female & \\
\cline { 2 - 3 } \cline { 5 - 6 } & Migraine & TTH & & Migraine & TTH \\
\hline $18-29$ & $15.3 \%(110)$ & $47.4 \%(342)$ & & $20.1 \%(164)$ & $36.8 \%(300)$ \\
$30-39$ & $17.8 \%(74)$ & $53.0 \%(220)$ & & $24.6 \%(162)$ & $44.5 \%(293)$ \\
$40-49$ & $20.6 \%(90)$ & $59.2 \%(258)$ & & $38.3 \%(164)$ & $34.8 \%(149)$ \\
$50-59$ & $20.7 \%(60)$ & $47.9 \%(139)$ & & $36.4 \%(96)$ & $30.7 \%(81)$ \\
$60-65$ & $19.4 \%(24)$ & $47.6 \%(59)$ & $22.1 \%(15)$ & $35.3 \%(24)$ \\
\hline
\end{tabular}

$\pi \mathrm{H}$ tension-type headache who are inevitably excluded from household surveys while making up an estimated $45.5 \%$ of the urban population according to some statistics [21]. These are people below the poverty line, in whom, if the association with poverty holds (see below), headache will be common.

This study was one of a series being conducted by LTB in pursuit of the Global Campaign against Headache. While several of these are not yet completed or fully analyzed, the careful enquiry incorporated into the methodology of these studies is finding that headache prevalences have in the past been significantly underestimated. For example, very similar findings have emerged from India, a country which shares Pakistan's genetic, environmental and cultural composition: the 1-year prevalence in Karnataka State of all headache was $63.9 \%$, of migraine $25.2 \%$ (with a $4: 3$ female preponderance)

Table 3 Bivariate analysest to demonstrate potential associations between headache types and demographic factors, habitation and body mass index

\begin{tabular}{|c|c|c|c|c|c|}
\hline \multirow[t]{2}{*}{ Variable $(N=4223)$} & \multicolumn{5}{|c|}{ Odds ratios (95\% confidence intervals) } \\
\hline & $\begin{array}{l}\text { All headache } \\
(n=3233)\end{array}$ & $\begin{array}{l}\text { Migraine } \\
(n=967)\end{array}$ & $\begin{array}{l}\text { Tension-type headache } \\
(n=1887)\end{array}$ & $\begin{array}{l}\text { Probable } \mathrm{MOH} \\
(n=30)\end{array}$ & $\begin{array}{l}\text { Other headache on } \geq 15 \mathrm{~d} / \mathrm{m} \\
(n=312)\end{array}$ \\
\hline \multicolumn{6}{|l|}{ Age } \\
\hline $18-29$ years $(n=1537)$ & Reference & Reference & Reference & Reference & Reference \\
\hline $30-39$ years $(n=1074)$ & $1.8(1.5-2.1)^{*}$ & $1.3(1.1-1.6)^{*}$ & $1.3(1.1-1.5)^{*}$ & $0.7(0.2-2.1)$ & $1.1(0.9-1.5)$ \\
\hline $40-49$ years $(n=865)$ & $2.5(2.1-3.1)^{*}$ & $1.8(1.4-2.3)^{*}$ & $1.2(1.1-1.5)^{*}$ & $1.1(0.4-3.0)$ & $0.9(0.7-1.3)$ \\
\hline $50-59$ years $(n=554)$ & $1.9(1.5-2.4)^{*}$ & $1.8(1.4-2.3)^{*}$ & $0.9(0.8-1.1)$ & $2.0(0.7-5.2)$ & $1.3(0.9-1.8)$ \\
\hline $60-65$ years $(n=193)$ & $1.5(1.1-2.1)^{*}$ & $1.2(0.8-1.7)$ & $1.1(0.8-1.4)$ & $3.3(1.0-10.5)^{*}$ & $1.4(0.8-2.3)$ \\
\hline \multicolumn{6}{|l|}{ Marital status ( $N=4182 ;$ missing 41$)$} \\
\hline Single $(n=1309)$ & Reference & Reference & Reference & Reference & Reference \\
\hline Married $(n=2637)$ & $1.8(1.5-2.1)^{*}$ & $1.5(1.3-1.8)^{*}$ & $1.1(1.0-1.3)$ & $1.8(0.7-4.5)$ & $1.1(0.8-1.4)$ \\
\hline Divorced, widowed or separated $(n=236)$ & $1.9(1.4-2.7)^{*}$ & $1.8(1.3-2.5)^{*}$ & $0.7(0.5-0.9)^{*}$ & - & $2.5(1.6-3.7)^{*}$ \\
\hline \multicolumn{6}{|l|}{ Habitation $(N=4223)$} \\
\hline Rural $(n=2780)$ & Reference & Reference & Reference & Reference & Reference \\
\hline Urban $(n=1443)$ & $1.0(0.9-1.2)$ & $1.2(1.0-1.4)$ & $0.7(0.6-0.8)^{*}$ & $1.9(0.9-4.2)$ & $1.8(1.4-2.3)^{*}$ \\
\hline \multicolumn{6}{|l|}{ Educational level ( $N=3263$; missing 960$)$} \\
\hline None $(n=600)$ & Reference & Reference & Reference & Reference & Reference \\
\hline Some schooling $(n=2454)$ & $1.2(1.0-1.4)$ & $0.5(0.4-0.7)^{*}$ & $2.2(1.8-2.6)^{*}$ & $1.2(0.4-3.6)$ & $0.6(0.4-0.8)^{*}$ \\
\hline College $(n=209)$ & $0.6(0.4-0.8)^{*}$ & $0.5(0.3-0.7)^{*}$ & $1.5(1.1-2.1)^{*}$ & - & $0.4(0.2-0.8)^{*}$ \\
\hline \multicolumn{6}{|l|}{ Income level ( $N=3606$; missing 617) } \\
\hline Poor $(n=1127)$ & Reference & Reference & Reference & Reference & Reference \\
\hline Not poor $(n=2479)$ & $0.7(0.6-0.9)^{*}$ & $0.8(0.7-0.9)^{*}$ & $1.3(1.1-1.5)^{*}$ & $0.8(0.3-1.7)$ & $0.4(0.3-0.5)^{*}$ \\
\hline \multicolumn{6}{|l|}{ Body mass index ( $N=3889$; missing 334$)$} \\
\hline Normal $(n=2152)$ & Reference & Reference & Reference & Reference & Reference \\
\hline Underweight $(n=155)$ & $0.6(0.4-1.0)^{*}$ & $1.7(1.1-2.5)^{*}$ & $0.4(0.3-0.7)^{*}$ & $1.8(0.4-8.2)$ & $1.2(0.6-2.1)$ \\
\hline Overweight ( $n=1156$ ) & $1.0(0.8-1.2)$ & $1.2(1.0-1.4)$ & $0.9(0.7-1.0)$ & $0.9(0.4-2.2)$ & $1.0(0.7-1.3)$ \\
\hline Obese $(n=417)$ & $0.6(0.5-0.8)^{*}$ & $1.6(1.3-2.1)^{*}$ & $0.4(0.3-0.5)^{*}$ & $0.3(0.04-2.1)$ & $1.5(1.0-2.2)^{*}$ \\
\hline Morbidly obese $(n=9)$ & $0.2(0.15-0.25)^{*}$ & $1.6(1.3-2.1)^{*}$ & $0.4(0.3-0.5)^{*}$ & $1.1(0.3-4.0)$ & $0.7(0.4-1.2)$ \\
\hline
\end{tabular}


Table 4 Multivariate analysis of associations between headache types and demographic and environmental factors and body mass index

\begin{tabular}{|c|c|c|c|}
\hline \multirow[t]{2}{*}{ Variable } & \multicolumn{3}{|c|}{ Exp(B) (95\% confidence intervals) } \\
\hline & $\begin{array}{l}\text { Migraine } \\
(n=967)\end{array}$ & $\begin{array}{l}\text { Tension-type headache } \\
(n=1887)\end{array}$ & $\begin{array}{l}\text { Headache on } \geq 15 \mathrm{~d} / \mathrm{m} \\
(n=342)\end{array}$ \\
\hline \multicolumn{4}{|c|}{ Gender $(N=4223)$ compared to male $(n=1957)$} \\
\hline $\begin{array}{l}\text { Female } \\
(n=2266)\end{array}$ & $\begin{array}{l}1.3(1.01-1.7) \\
P=0.039\end{array}$ & $\begin{array}{l}0.8(0.7-0.97) \\
P=0.026\end{array}$ & $\begin{array}{l}2.0(1.4-2.9) \\
P<0.001\end{array}$ \\
\hline \multicolumn{4}{|c|}{ Age $(N=4223)$ compared to $18-29$ years $(n=1507)$} \\
\hline $\begin{array}{l}\text { 30-39 years } \\
(n=1197)\end{array}$ & $\begin{array}{l}0.9(0.6-1.3) \\
P=0.522\end{array}$ & $\begin{array}{l}1.5(1.1-2.0) \\
P=\mathbf{0 . 0 1 2}\end{array}$ & $\begin{array}{l}1.2(0.7-2.0) \\
P=0.536\end{array}$ \\
\hline $\begin{array}{l}40-49 \text { years } \\
(n=1101)\end{array}$ & $\begin{array}{l}2.0(1.3-2.9) \\
P=\mathbf{0 . 0 0 1}\end{array}$ & $\begin{array}{l}2.4(1.7-3.4) \\
\boldsymbol{P}<0.001\end{array}$ & $\begin{array}{l}2.0(1.2-3.5) \\
P=\mathbf{0 . 0 1 5}\end{array}$ \\
\hline $\begin{array}{l}50-59 \text { years } \\
(n=330)\end{array}$ & $\begin{array}{l}1.1(0.6-2.1) \\
P=0.720\end{array}$ & $\begin{array}{l}1.4(0.8-2.3) \\
P=0.201\end{array}$ & $\begin{array}{l}2.0(0.9-4.4) \\
P=0.076\end{array}$ \\
\hline $\begin{array}{l}60-65 \text { years } \\
(n=88)\end{array}$ & $\begin{array}{l}2.1(0.7-6.7) \\
P=0.201\end{array}$ & $\begin{array}{l}2.8(1.1-7.1) \\
P=0.034\end{array}$ & $\begin{array}{l}1.8(0.3-9.4) \\
P=0.515\end{array}$ \\
\hline \multicolumn{4}{|c|}{ Marital status ( $N=4182$; missing 41) compared to single $(n=1089)$} \\
\hline $\begin{array}{l}\text { Married } \\
(n=3015)\end{array}$ & $\begin{array}{l}1.8(1.2-2.5) \\
P=\mathbf{0 . 0 0 2}\end{array}$ & $\begin{array}{l}1.3(0.9-1.7) \\
P=0.115\end{array}$ & $\begin{array}{l}1.2(0.7-2.0) \\
P=0.490\end{array}$ \\
\hline $\begin{array}{l}\text { Divorced, widowed or separated } \\
(n=78)\end{array}$ & $\begin{array}{l}0.5(0.1-1.8) \\
P=0.277\end{array}$ & $\begin{array}{l}0.8(0.3-2.0) \\
P=0.683\end{array}$ & $\begin{array}{l}1.4(0.5-4.3) \\
P=0.568\end{array}$ \\
\hline \multicolumn{4}{|c|}{ Habitation $(N=4223)$ compared to rural $(n=2780)$} \\
\hline $\begin{array}{l}\text { Urban } \\
(n=1443)\end{array}$ & $\begin{array}{l}1.3(1.0-1.7) \\
P=0.053\end{array}$ & $\begin{array}{l}1.1(0.9-1.3) \\
P=0.554\end{array}$ & $\begin{array}{l}1.0(0.7-1.5) \\
P=0.895\end{array}$ \\
\hline \multicolumn{4}{|c|}{ Educational level ( $N=3277$; missing 946) compared to none $(n=166)$} \\
\hline $\begin{array}{l}\text { Some schooling } \\
(n=2691)\end{array}$ & $\begin{array}{l}0.8(0.5-1.2) \\
p=0.263\end{array}$ & $\begin{array}{l}1.8(1.2-2.9) \\
\boldsymbol{p}=\mathbf{0 . 0 1 1}\end{array}$ & $\begin{array}{l}1.3(0.7-2.4) \\
p=0.503\end{array}$ \\
\hline $\begin{array}{l}\text { College } \\
(n=420)\end{array}$ & $\begin{array}{l}0.4(0.2-0.8) \\
\boldsymbol{p}=\mathbf{0 . 0 0 4}\end{array}$ & $\begin{array}{l}1.0(0.6-1.7) \\
p=0.959\end{array}$ & $\begin{array}{l}0.9(0.4-2.0) \\
p=0.721\end{array}$ \\
\hline \multicolumn{4}{|c|}{ Income level ( $N=3606$; missing 617) compared to poor $(n=1127)$} \\
\hline $\begin{array}{l}\text { Not poor } \\
(n=2479)\end{array}$ & $\begin{array}{l}0.5(0.4-0.7) \\
p<0.001\end{array}$ & $\begin{array}{l}0.8(0.6-1.01) \\
p=0.061\end{array}$ & $\begin{array}{l}0.3(0.2-0.5) \\
\boldsymbol{p}<\mathbf{0 . 0 0 1}\end{array}$ \\
\hline \multicolumn{4}{|c|}{ Province $(N=4223)$ compared to Punjab $(n=2431)$} \\
\hline $\begin{array}{l}\text { Sindh } \\
(n=1017)\end{array}$ & $\begin{array}{l}1.0(0.8-1.4) \\
P=0.781\end{array}$ & $\begin{array}{l}0.7(0.5-0.9) \\
P=\mathbf{0 . 0 0 2}\end{array}$ & $\begin{array}{l}2.2(1.5-3.4) \\
P<0.001\end{array}$ \\
\hline $\begin{array}{l}\text { Baluchistan } \\
(n=201)\end{array}$ & $\begin{array}{l}0.5(0.2-0.9) \\
P=0.022\end{array}$ & $\begin{array}{l}0.5(0.3-0.9) \\
P=\mathbf{0 . 0 1 1}\end{array}$ & $\begin{array}{l}2.7(1.2-5.9) \\
P=\mathbf{0 . 0 1 3}\end{array}$ \\
\hline $\begin{array}{l}\text { Khyber Pakhtunkhwa } \\
(n=574)\end{array}$ & $\begin{array}{l}0.2(0.1-0.3) \\
P<0.001\end{array}$ & $\begin{array}{l}0.4(0.3-0.6) \\
P<0.001\end{array}$ & $\begin{array}{l}0.5(0.3-1.1) \\
P=0.077\end{array}$ \\
\hline \multicolumn{4}{|c|}{ Body mass index ( $N=3889 ;$ missing 334$)$ compared to normal $(n=2152)$} \\
\hline $\begin{array}{l}\text { Underweight } \\
(n=155)\end{array}$ & $\begin{array}{l}0.8(0.4-1.4) \\
P=0.412\end{array}$ & $\begin{array}{l}0.5(0.3-0.8) \\
P=\mathbf{0 . 0 0 5}\end{array}$ & $\begin{array}{l}1.4(0.7-2.9) \\
P=0.386\end{array}$ \\
\hline $\begin{array}{l}\text { Overweight } \\
(n=1156)\end{array}$ & $\begin{array}{l}1.2(0.9-1.6) \\
P=0.193\end{array}$ & $\begin{array}{l}1.0(0.8-1.3) \\
P=1.00\end{array}$ & $\begin{array}{l}1.3(0.8-1.9) \\
P=0.298\end{array}$ \\
\hline $\begin{array}{l}\text { Obese or morbidly obese } \\
(n=426)\end{array}$ & $\begin{array}{l}0.9(0.6-1.4) \\
P=0.573\end{array}$ & $\begin{array}{l}0.4(0.3-0.6) \\
\boldsymbol{P}<0.001\end{array}$ & $\begin{array}{l}1.4(0.8-2.6) \\
P=0.249\end{array}$ \\
\hline
\end{tabular}

Significant associations $(P<0.02)$ are emboldened. $d / m$ days/month

and of TTH $35.1 \%$ [22]. Also in Nepal, a similar nationwide study found 1-year prevalences of all headache of $84.9 \%$, of migraine $34.1 \%$ and of TTH $41.5 \%$ [12], and in Russia, another similar study found prevalences of $62.9 \%$ for all headache, $20.8 \%$ for migraine and $30.8 \%$ for $\mathrm{TTH}$
[9]. It would therefore be incorrect to suggest, although they are very common in Pakistan, that headache in general and migraine in particular are excessively prevalent in this country. The reality is that these are very common disorders worldwide, to a degree that is only now 
being recognised. Only in the Far East does evidence persist of lower prevalence: for example, $23.8 \%$ for all primary headache and $9.3 \%$ for migraine from a similar nationwide study supported by LTB in China [10]. Whether the reasons for this are genetic, environmental or cultural is yet to be ascertained.

The prevalence in Pakistan of all causes of headache on $\geq 15$ days/month $(8.1 \%)$ is approaching three times the estimated global average of 3\% [1], but still not outside the range found by similar studies. It is similar in Nepal (7.4\%) [12] and Georgia (7.6\%) [23], and appreciably higher in Russia (10.4\%) [9], but lower in India (3.0\%) [22]. In Russia, but apparently not Georgia, much of this is associated with medication overuse, and therefore reported as $\mathrm{pMOH}$, with prevalences of $7.2 \%$ and $0.9 \%$ respectively. In India, the prevalence of $\mathrm{pMOH}$ is $1.2 \%$ [22] and in Nepal it is 2.1\% [12] against Pakistan's $0.7 \%$. Pakistan therefore mirrors Georgia - also a lowermiddle-income country - in this respect. This level of highly-frequent headache in Pakistan must be a cause of concern, for it signals much public ill health. A crosssectional survey cannot establish the causes: these require investigation in clinical settings, although, as in Georgia, medication overuse does not appear to be the major factor. Studies elsewhere suggest multiple factors [24], including high consumption of caffeine (which is present in black tea, typically consumed many times a day in Pakistan) and various health-related issues such as asthma, hypothyroidism and hypertension. Pakistan's unrecognized public ill health and disability warrant enquiry into these factors.

There were some associations of interest. As everywhere [1], observed prevalence of migraine was higher in females than in males, reflecting a female predisposition understood to be hormonally determined [25]. However, the ratio was only $1.5: 1$ (26.9\% versus $18.0 \%)$ and multivariate analysis found female gender, with $\operatorname{Exp}(B)=1.3$, to be only barely significant $(P=0.039)$. It may be noted, as a plausible explanation, that the culture of Pakistan expects women's interviews to be conducted in their husbands' presence while, at the same time, discouraging women from expressing pain in front of their husbands (neurologists in Pakistan are familiar with anecdotal accounts of husbands seeking divorce from their wives on account of their "constant complaints" of headache). In other words, migraine may have been somewhat under-reported by women. Speculatively, the same may have occurred, to a greater degree, with TTH, a disorder perhaps more easily hidden than migraine: in contrast to most studies elsewhere, we found in Pakistan a significantly higher prevalence of TTH in males (51.2\%) than in females (37.9\%), although this difference, with $\operatorname{Exp}(B)=0.8$, was also barely significant $(P=0.026)$ after correction for other factors. Comment is still needed on why the prevalence of TTH in males $(51.2 \%)$ is unusually high - more than in India, and even Nepal, where prevalence was again higher in males (44.6\%) than females (38.7\%) [12]. This finding occurred consistently in every city surveyed except Sukkur $(n=81)$. The male:female working ratio is very high in Pakistan [26]; the burden of supporting the entire household falls almost solely on the male. Whether or not this is a relevant factor may emerge in future studies in other mostly patriarchal countries: preliminary results from Saudi Arabia (unpublished) show a similar trend.

Age had differential impacts on headache types and in the genders. For migraine, the trends were slightly different in males and females, with a more significant effect seen in females (Table 2). Migraine in females increased from adolescence (18-29 years) to middle age (30-49), declining slightly in the perimenopausal years (50-59) and sharply decreasing in the postmenopausal age group of 60-65. These trends can be attributed to the welldocumented influence on migraine of oestrogen levels [25]. For TTH, prevalence peaked later in males (40-49) than in females (30-39).

The associations with educational level were complex and not easily explained, except to the extent that they matched those of income level (these two factors themselves being strongly correlated, although each retained some independent associations with the probabilities of migraine and TTH in multivariate analysis [Table 4]). Poverty by itself was positively associated with migraine and headache on $\geq 15$ days/month and negatively with TTH, although the last observation did not hold true after multivariate analysis. In general, therefore, it seems migraine is associated with lower socioeconomic status (SES), being significantly less prevalent among the collegeeducated and not poor. Educational and income levels affect lifestyle, diet, stress and general hardship levels and, of course, general health and access to health care, so that the social causation hypothesis is speculatively invoked to explain this association [27]: lower SES brings stress and other disease mediators that increase the incidence or duration of illness. The association between poverty and headache has been noted elsewhere $[9,23,28]$.

The differences between provinces are noteworthy. Punjab and Sindh have more migraine than Khyber Pakhtunkhwa and, probably, Baluchistan, whereas Punjab has more TTH than all other provinces. Yet headache on $\geq 15$ days/month is more common in Sindh and Baluchistan than in Punjab or, especially, Khyber Pakhtunkhwa. These differences are not easily explained. Each province is largely occupied by a different ethnic group: Punjabi, Sindhi, Baloch and Pashtun, although there are many minority groups. Punjab is an agricultural province with warmer weather; it has higher average SES, which appears contradictory to the trend for migraine but in line with 
that for headache on $\geq 15$ days/month. Khyber Pakhtunkhwa, which has least headache of all types, has more rural dwellings and a colder climate, and much of it is at high altitudes. In Nepal, increasing altitude, at least between sea level and 2,500 m, is correlated with increasing migraine prevalence [12]. Khyber Pakhtunkhwa is also beset by armed conflict and terrorism, which might be expected to increase rather than reduce headache levels. These differences warrant further investigation.

Associations with BMI were also complex, those of migraine and TTH again appearing to be in opposite directions. Such associations have been studied extensively [29-31]. Possible mechanisms to link migraine and headache on $\geq 15$ days/month with obesity have been described [30] and will not be commented on here. From a public-health perspective, it is of interest if obesity is a risk factor for these disorders since it is potentially modifiable (unlike age, gender and poverty). However, the positive association of obesity with migraine did not survive multivariate analysis, whereas the negative association with TTH remained strong $(\operatorname{Exp}(\mathrm{B}) 0.4 ; P<$ 0.001). Previous studies [32] have been unable to link TTH with BMI. Overall, not much can be made of these findings with respect to BMI, although it might be observed that obesity is quickly becoming a public-health problem in Pakistan [33].

There are limitations to our study. First, all weightings relied on data that are almost twenty years old given that Pakistan's last census was in 1998 [20]. Second, as noted earlier, we could not reach almost $45 \%$ of the urban population who were slum-dwelling [21], which potentially introduced a bias. Third, because of the security situation in Pakistan during the conduct of this study, we were unable to access Quetta, the largest city in Baluchistan province, and areas north of Abbotabad in the Khyber Pakhtunkhwa province. The same concern limited us from going into the deep rural population. Whether these restrictions led to appreciable bias is unknown.

What is the importance of these findings to Pakistan? It is clear that headache disorders in this country are extremely prevalent in absolute terms, and high also relative to global means. These facts were not previously known. But Pakistan has many and considerable public-health problems [32], and prevalence alone does not establish a case for priority. In this regard it can be noted that migraine is the sixth highest cause of disability in the world [3] and Pakistan has much more migraine than the world on average. Burden data will be reported in a future publication.

\section{Conclusion}

With over three quarters of its population affected, headache disorders must be on the public-health agenda of Pakistan. Worldwide, these disorders are the third leading cause of disability [6]; information from specific enquiry into the burden attributable to headache disorders in this country is needed to inform health policy and priority-setting, and will be reported soon.

\section{Funding}

The study was supported by Lifting The Burden, a United Kingdom-based non-governmental organization conducting the Global Campaign against Headache in official relations with the World Health Organization.

\section{Authors' contributions}

ADH and TJS conceived the study. TJS drafted the protocol and study questionnaire, which were subsequently refined by TJS and ADH in discussion. ADH provided supervision in Pakistan. AAH, AA, ULU, BA, JE, SZA and RK were responsible for conduct of the study in the field, with ADH acting as principal investigator. UJ and MAS carried out the statistical analysis. AAH and TJS drafted the manuscript. All authors reviewed and approved the final version.

\section{Competing interests}

TJS is a Director and Trustee of Lifting The Burden. There were no other conflicts of interest.

\section{Author details}

${ }^{1}$ Headache Research Foundation of Pakistan, Karachi, Pakistan. ${ }^{2}$ Department of Surgery, University of Texas at San Antonio, San Antonio, TX, USA. ${ }^{3}$ Dow University of Health Sciences, Karachi, Pakistan. ${ }^{4}$ Department of Neurology, Center for Movement Disorders and Neurorestoration, University of Florida College of Medicine, Gainesville, FL, USA. ${ }^{5}$ Department of Medicine, University of Nevada, Las Vegas, USA. ${ }^{6}$ Aga Khan Medical College, Aga Khan Medical University Hospital, Karachi, Pakistan. ${ }^{7}$ School of International and Public Affairs, Columbia University, New York, NY, USA. ${ }^{8}$ Department of Neurology, Baqai Medical University, Karachi, Pakistan. ${ }^{9}$ Department of Pathology and Microbiology Department at Dow University of Health Sciences, Karachi, Pakistan. ${ }^{10}$ Department of Neuroscience, Norwegian University of Science and Technology (NTNU), Edvard Griegs Gate, NO-7491 Trondheim, Norway. ${ }^{11}$ Division of Brain Sciences, Imperial College London, London, UK.

Received: 19 January 2017 Accepted: 8 February 2017 Published online: 23 February 2017

\section{References}

1. Stovner LJ, Hagen K, Jensen R, Katsarava Z, Lipton R, Scher A, Steiner T, Zwart JA (2007) The global burden of headache: a documentation of headache prevalence and disability worldwide. Cephalalgia 27:193-210

2. Vos T, Flaxman AD, Naghavi M, Lozano R, Michaud C, Ezzati M, Shibuya K, Salomon JA, Abdalla S, Aboyans V, Abraham J, Ackerman I, Aggarwal R, Ahn SY, Ali MK, Alvarado M, Anderson HR, Anderson LM, Andrews KG, Atkinson C, Baddour LM, Bahalim AN, Barker-Collo S, Barrero LH, Bartels DH, Basáñez MG, Baxter A, Bell ML, Benjamin EJ, Bennett D et al (2012) Years lived with disability (YLDs) for 1160 sequelae of 289 diseases and injuries 1990-2010: a systematic analysis for the Global Burden of Disease Study 2010. Lancet 380: 2163-2196

3. Global Burden of Disease Study Collaborators (2015) Global, regional, and national incidence, prevalence, and years lived with disability for 301 acute and chronic diseases and injuries in 188 countries, 1990-2013: a systematic analysis for the Global Burden of Disease Study 2013. Lancet 386:743-800

4. Headache Classification Committee of the International Headache Society (2013) The international classification of headache disorders, 3rd edition (beta version). Cephalalgia 33:629-808

5. World Health Organization and Lifting The Burden (2011) Atlas of headache disorders and resources in the world 2011. WHO Press, Geneva

6. Steiner TJ, Birbeck GL, Jensen RH, Katsarava Z, Stovner LJ, Martelletti $P$ (2015) Headache disorders are third cause of disability worldwide. J Headache Pain 16:58

7. Steiner TJ (2004) Lifting the burden: The global campaign against headache Lancet-Neurology 3:204-205

8. Steiner TJ, Birbeck GL, Jensen R, Katsarava Z, Martelletti P, Stovner LJ (2010) Lifting The Burden: the first 7 years. J Headache Pain 11:451-455 
9. Ayzenberg I, Katsarava Z, Sborowski A, Chernysh M, Osipova V, Tabeeva G, Yakhno N, Steiner TJ (2012) The prevalence of primary headache disorders in Russia: a countrywide survey. Cephalalgia 32:373-381

10. Yu S, Liu R, Zhao G, Yang X, Qiao X, Feng J, Fang Y, Cao X, He M, Steiner T (2012) The prevalence and burden of primary headaches in China: a population-based door-to-door survey. Headache 52:582-591

11. Rao GN, Kulkarni GB, Gururaj G, Rajesh K, Subbakrishna DK, Steiner TJ, Stovner $L$ (2012) The burden of headache disorders in India: methodology and questionnaire validation for a community-based survey in Karnataka State. J Headache Pain 13:543-550

12. Manandhar K, Risal A, Linde M, Steiner TJ (2016) The burden of headache disorders in Nepal: estimates from a population-based survey. J Headache Pain 17:3

13. United Nations Department of Economic and Social Affairs, Population Division (2015) World population prospects: the 2015 revision. Key findings and advance tables (Working Paper No ESA/PMP241). United Nations, New York

14. Stovner LJ, Al Jumah M, Birbeck GL, Gururaj G, Jensen R, Katsarava Z, Queiroz LP, Scher Al, Tekle-Haimanot R, Wang SJ, Steiner TJ (2014) The methodology of population surveys of headache prevalence, burden and cost: principles and recommendations from the Global Campaign against Headache. J Headache Pain 15:5

15. Herekar AD, Herekar AA, Ahmad A, Uqaili UL, Ahmed B, Effendi J, Alvi SZ, Steiner TJ (2013) The burden of headache disorders in Pakistan: methodology of a population-based nationwide study, and questionnaire validation. J Headache Pain 14:73

16. Steiner TJ, Gururaj G, Andrée C, Katsarava Z, Ayzenberg I, Yu S-Y, Al Jumah M, Tekle-Haimanot R, Birbeck GL, Herekar A, Linde M, Mbewe E, Manandhar K, Risal A, Jensen R, Queiroz LP, Scher Al, Wang SJ, Stovner LJ (2014) Diagnosis, prevalence estimation and burden measurement in population surveys of headache: presenting the HARDSHIP questionnaire. J Headache Pain 15:3

17. The World Bank (2013) Poverty headcount ratio at national poverty lines (\% of population)(Pakistan). World Bank, Washington DC, http://data.worldbank. org/indicator/SI.POV.NAHC?locations=PK (last accessed 11 Jan 2017)

18. World Health Organization (2016) Obesity and overweight. Fact sheet 311 (updated June 2016). World Health Organization, Geneva, http://www.who. int/mediacentre/factsheets/fs311/en/ (last accessed 21 Dec 2016)

19. Ahmed B, Ahmad A, Herekar AA, Uqaili UL, Effendi J, Alvi SZ, Herekar AD, Steiner TJ (2014) Fraud in a population-based study of headache: prevention, detection and correction. J Headache Pain 15:37

20. Pakistan Bureau of Statistics (2016) Population census 1998 (updated December 2016). Government of Pakistan, Islamabad, http://www.pbs.gov. pk/population-tables (last accessed 21 Dec 2016)

21. United Nations Statistics Division (2016) Slum population as percentage of urban (Pakistan 2014) (updated February 2016). United Nations, New York, http://data.un.org/Data.aspx?d=MDG\&f=seriesRowID\%3a710 (last accessed 21 Dec 2016)

22. Kulkarni GB, Rao GN, Gururaj G, Stovner LJ, Steiner TJ (2015) Headache disorders and public ill-health in India: prevalence estimates in Karnataka State. J Headache Pain 16:67

23. Katsarava Z, Dzagnidze A, Kukava M, Mirvelashvili E, Djibuti M, Janelidze M, Jensen R, Stovner LJ, Steiner TJ (2009) Primary headache disorders in the Republic of Georgia: prevalence and risk factors. Neurology 73:1796-1803

24. Bigal ME, Sheftell FD, Rapoport AM, Tepper SJ, Lipton RB (2002) Chronic daily headache: identification of factors associated with induction and transformation. Headache 42:575-581

25. Brandes $J L$ (2006) The influence of estrogen on migraine: a systematic review. JAMA 295:1824-1830

26. World Bank Group (2016) Ratio of female to male labor force participation rate (\%) (modeled ILO estimate) (Pakistan). World Bank, Washington DC, http://data.worldbank.org/indicator/SL.TLF.CACT.FM.ZS?locations=PK (last accessed 21 Dec 2016)

27. Stewart WF, Roy J, Lipton RB (2013) Migraine prevalence, socioeconomic status, and social causation. Neurology 81:948-955

28. Winter AC, Berger K, Buring JE, Kurth T (2012) Associations of socioeconomic status with migraine and non-migraine headache. Cephalalgia 32:159-170

29. Bigal ME, Liberman JN, Lipton RB (2006) Obesity and migraine: a population study. Neurology 66:545-550

30. Bigal ME, Lipton RB, Holland PR, Goadsby PJ (2007) Obesity, migraine, and chronic migraine: possible mechanisms of interaction. Neurology 68:1851-1861
31. Keith SW, Wang C, Fontaine KR, Cowan CD, Allison DB (2008) BMI and headache among women: results from 11 epidemiologic datasets. Obesity 16:377-383

32. Bigal ME, Tsang A, Loder E, Serrano D, Reed ML, Lipton RB (2007) Body mass index and episodic headaches: a population-based study. Arch Intern Med 167:1964-1970

33. Nanan DJ (2002) The obesity pandemic - implications for Pakistan. J Pakistan Med Assoc 52:342-346

\section{Submit your manuscript to a SpringerOpen ${ }^{\circ}$ journal and benefit from:}

- Convenient online submission

- Rigorous peer review

- Immediate publication on acceptance

- Open access: articles freely available online

- High visibility within the field

- Retaining the copyright to your article

Submit your next manuscript at $>$ springeropen.com 